NAMES, Vol. 56, No. 3, September, 2008, 109-110

\title{
Editorial
}

\section{FRANK NUESSEL}

University of Louisville

In the first issue of Names: A Journal of Onomastics published by Maney Publishing (volume 56, number I), I invited readers to identify the languages in which the word for names appeared. The languages are: German, Chinese, Yucatan Mayan, Italian, Greek, Old Norse, Nahuatl, Irish, Sanskrit, Korean, Algonquin, Hindi, Tamil, Turkish, Japanese, Arabic, French, Hebrew and Russian.

I began my pre-editorial duties in July of 2007. My official appointment as Editor started on January I, 2008. During the period of July I 5, 2007 to December 3I, 2007, I received 26 manuscripts for evaluation. Seventeen were accepted for publication subject to revision. Of these 17 manuscripts, I I authors responded in a timely fashion to the comments of the anonymous reviewers. Six, however, have not sent a revised document. Of these 6 , all required quite substantial revision. Nine submissions were rejected.

It is worth restating the procedures for submitting an article to NAMES at this point. A few suggestions to contributors are in order. First, submissions should follow the Names style sheet available at the American Name Society Web Site: http:// www.wtsn.binghamton.edu/ans/. Second, it is very helpful to ask one or two colleagues to read your submission carefully and critically prior to sending it to the Editor of Names so that any issues of grammar and content may be addressed beforehand. Third, all submissions must be submitted electronically by sending them to my email address (fhnues01@louisville.edu) together with an explanatory email. Fourth, once contributors receive the external evaluators' comments, it is important that they address all of the points raised in their revisions in order to facilitate the process. Failure to address the points raised by the external reviewers will result in substantial delay and possible rejection. Finally, any revisions specified by the outside reviewers should be addressed in a timely fashion, i.e. within four weeks.

In addition to the previous points about submissions to Names, it is advisable to do the following in order to avoid long delay or rejection:

- Read carefully the 'Notes for Contributors' located on the inside back cover for complete guidance about typescript preparation and follow the most recent edition of The Chicago Manual of Style (Chicago: University of Chicago Press). Use Microsoft Word for submissions. Do not send previously published work, or a work scheduled to appear in another publication at a future date, since it cannot be considered for republication. Articles should be no longer than twenty double-spaced pages in twelve-point Times New Roman typeface. Supply an abstract of I00-I50 words and up to 7 key words for articles. Attach 
a 50 word (maximum) biographical statement to the end of your article. Be sure to include complete contact information for you and your co-author(s). This information should include telephone number(s), email address(es), and regular mail address(es). If you plan to be away from your office for an extended period of time, you will need to include pertinent contact information. Respond to page proof corrections within one week. If you do not do this, your article will have to be removed at great cost and loss of time to the journal.

- Check grammar, syntax and spelling very carefully. The use of Spell Check on your computer does not capture all of the errors, i.e. a correctly spelled word may not be appropriate for a particular grammatical context. An example of this is 'her', a correctly spelled English word, even though you meant 'here'. Use American spelling conventions, e.g., "color" not "colour"; "center" not "centre", and so forth.

- Use only those diacritics that are compatible with Microsoft Word, go to "Insert Symbol" in Word for the full array of possible characters including the Greek and Arabic alphabets etc.

- Check the textual references very carefully. Be certain that all references in the text appear in the reference section. Cite page references in the text, not just year of publication. Readers will want to know where they can locate a specific reference. Use single columns for notes.

- Check and double-check all Tables and Figures very carefully. Be sure that the mathematics and statistics are correct. Ask a colleague to recheck them. Images should be supplied digitally in CMYK format as either TIF or EPS files, suitable for printing. As a guide images should be submitted at a minimum input scanning resolution of $300 \mathrm{dpi}$ for full color, $35^{\circ}-400 \mathrm{dpi}$ for half tones, $600 \mathrm{dpi}$ for slide or transparency, $800 \mathrm{dpi}$ for simple line and I200 dpi for fine line illustrations.

- Authors who wish to reproduce material from previously published sources or where the copyright is owned by a third party, such as sections of text, tables or images, must obtain written permission from the copyright holder (usually the publisher) and the author(s)/artist(s) of the original material. A line giving the full source of the material should be included in the manuscript. Copyright is required for use in all formats (including digital), in perpetuity and in all geographical regions worldwide.

- Any reproduction from Names: A Journal of Onomastics, apart from for the purposes of review, private research or 'fair dealing', must have the permission of The American Name Society. Requests for such permission must be addressed to Permissions Section, Maney Publishing at: permissions@maney.co.uk, who act on behalf of the Society. In all cases, acknowledgement must be made to Names: A Journal of Onomastics.

We hope that you will consider submitting your onomastic research to Names for consideration for publication. 